\title{
Opioid prescribing by multiple providers in Medicare: retrospective observational study of insurance claims
}

\author{
(c) $(1)(9)$ OPEN ACCESS
}

\author{
Anupam B Jena assistant professor of healthcare policy and medicine ${ }^{123}$, Dana Goldman Leonard \\ $D$ Schaeffer chair in medicine and public policy ${ }^{4}$, Lesley Weaver graduate student ${ }^{5}$, Pinar \\ Karaca-Mandic assistant professor ${ }^{5}$
}

${ }^{1}$ Department of Health Care Policy, Harvard Medical School, 180 Longwood Avenue, Boston, MA 02115, USA; ${ }^{2}$ Department of Medicine, Massachusetts General Hospital, 55 Fruit Street, Boston, MA 02114, USA; ${ }^{3}$ National Bureau of Economic Research, 1050 Massachusetts Avenue, Cambridge, MA 02138, USA; ' ${ }^{4}$ eonard D Schaeffer Center for Health Policy and Economics, University of Southern California, 3335 South Figueroa, Unit A, Los Angeles, CA 90089, USA ; 5 University of Minnesota, School of Public Health, Division of Health Policy and Management, 420 Delaware Street SE, MMC 729, Minneapolis, MN 55455, USA

\begin{abstract}
Objectives To estimate the frequency and characteristics of opioid prescribing by multiple providers in Medicare and the association with hospital admissions related to opioid use.

Design Retrospective cohort study.

Setting Database of prescription drugs and medical claims in $20 \%$ random sample of Medicare beneficiaries in 2010.

Participants 1808355 Medicare beneficiaries who filled at least one prescription for an opioid from a pharmacy in 2010.
\end{abstract}

Main outcome measures Proportion of beneficiaries who filled opioid prescriptions from multiple providers; proportion of these prescriptions that were concurrently supplied; adjusted rates of hospital admissions related to opioid use associated with multiple provider prescribing.

Results Among 1208100 beneficiaries with an opioid prescription, 418 530 (34.6\%) filled prescriptions from two providers, $171420(14.2 \%)$ from three providers, and 143344 (11.9\%) from four or more providers. Among beneficiaries with four or more opioid providers, 110671 (77.2\%) received concurrent opioid prescriptions from multiple providers, and the dominant provider prescribed less than half of the mean total prescriptions per beneficiary (7.9/15.2 prescriptions). Multiple provider prescribing was highest among beneficiaries who were also prescribed stimulants, non-narcotic analgesics, and central nervous system, neuromuscular, and antineoplastic drugs. Hospital admissions related to opioid use increased with multiple provider prescribing: the annual unadjusted rate of admission was $1.63 \%$ (95\% confidence interval 1.58 to $1.67 \%)$ for beneficiaries with one provider, $2.08 \%(2.03 \%$ to $2.14 \%)$ for two providers, $2.87 \%$ (2.77\% to $2.97 \%$ ) for three providers, and $4.83 \%$
$(4.70 \%$ to $4.96 \%)$ for four or more providers. Results were similar after covariate adjustment.

Conclusions Concurrent opioid prescribing by multiple providers is common in Medicare patients and is associated with higher rates of hospital admission related to opioid use.

\section{Introduction}

Use of prescription opioids by elderly people in the United States has grown considerably, ${ }^{1-4}$ driven by increasing rates of addiction, efforts to improve the undertreatment of chronic pain, ${ }^{5}$ the expansion of drug insurance to elderly people, and industry efforts to promote the use of prescription opioids. ${ }^{56}$ For example, the prevalence of long term use of prescription opioids among adults above age 65 in two large US healthcare systems increased from 5\% of patients in 1997 to $9 \%$ in $2005 .{ }^{3}$ Despite their therapeutic value in some clinical instances (such as pain associated with cancer and short term relief of acute pain not responsive to non-opioid analgesics), growing use of prescription opioids has emerged as a pressing public health problem in the $\mathrm{US},{ }^{78}$ in part due to public misconceptions about risks of addiction and safety. ${ }^{910}$ Across Americans of all ages, deaths from unintentional opioid overdose grew fourfold from 1999 to $2008,{ }^{11}$ largely because of prescription opioids. ${ }^{72}{ }^{13}$ Among elderly people, prescription opioids are associated with greater frequencies of fractures and ${ }^{14-16}$ safety events requiring admission to hospital ${ }^{15}$ and higher all cause mortality. ${ }^{15}$ Concerns about misuse of prescription opioids are not only limited to the US- the International Narcotics Control Board has advocated that misuse of prescription opioids is an international problem, 
as evidenced by growing rates of deaths related to opioid use in Canada, Australia, and the United Kingdom (where the number of deaths involving codeine and methadone nearly doubled between 2005 and 2009). ${ }^{17}$

Amid national concerns over opioid misuse and adverse effects of legitimate use, the frequency with which patients obtain opioid prescriptions from multiple healthcare providers (such as physicians, dentists, or, less commonly, physician assistants) rather than a single healthcare provider has received increasing attention in the US, ${ }^{18-24}$ not only because it might reflect the illicit procurement of opioids by patients intentionally seeking out multiple providers (that is, "doctor shopping") but because it might indicate fragmented patient care. ${ }^{25-28}$ Although much of the focus on multiple provider opioid prescribing has centered on opioid diversion (in which legally obtained opioids are transferred from a licit to an illicit channel of distribution or use), ${ }^{18-24}$ the ability of patients to receive opioid prescriptions from multiple physicians who do not or cannot communicate with one another can lead to fragmented prescribing of opioids, which is particularly concerning among elderly patients because of increased adverse events associated with opioid use ${ }^{7813}$ and high rates of polypharmacy in this population. ${ }^{29}{ }^{30}$ Despite this concern, however, there are no national estimates of the frequency of opioid prescribing by multiple providers in the US Medicare population, the characteristics of patients and physicians involved, and patient outcomes associated with multiple provider opioid prescribing. The US Medicare program is the primary source of insurance for Americans above the age of 65 and in 2012 insured nearly 50 million Americans, of whom about $83 \%$ were above the age of 65 .

Prior studies of multiple provider prescribing in the overall population suggest that prescribing of opioids by three or more healthcare providers within a year is common, with rates ranging from $10 \%$ to $15 \%$ of all individuals prescribed an opioid within a year. ${ }^{19-24}$ These studies have either been limited to state specific analyses ${ }^{1922} 24$ or have used national prescription databases but have not specifically analyzed the frequency of multiple provider opioid prescribing in Medicare, have not studied characteristics of patients and specialty of providers involved, have not focused on elderly and disabled people who are at greatest risk of adverse events associated with prescription opioid drugs, and, most importantly, have not analyzed adverse outcomes associated with multiple provider prescribing. ${ }^{183}$

Using data on the prescription drug claims of a national random sample of Medicare beneficiaries who filled a prescription for an opioid from a pharmacy in 2010, we estimated the frequency of multiple provider prescribing of opioids to Medicare beneficiaries, studied the characteristics of patients and providers involved, and estimated the association between multiple provider prescribing and admissions to hospital related to opioid use.

\section{Methods}

\section{Background on the US Medicare program}

The US Medicare program is the primary source of healthcare insurance for Americans above the age of 65 and for individuals aged under 65 with specific disabilities and conditions such as end stage renal disease requiring hemodialysis. In 2012, about $83 \%$ of Medicare's 50 million enrollees were above the age of 65 and the remaining younger enrollees had disabilities or specific clinical conditions as above. For each insured beneficiary, Medicare covers the costs of inpatient care through Medicare Part A, the costs of outpatient care through Medicare Part B, and the costs of prescription drug coverage through
Medicare Part D. While most Medicare enrollees receive their insurance through traditional Medicare-a system in which healthcare professionals and hospitals bill the US Centers for Medicare and Medicaid Services (CMS) directly for any care that is provided-about a quarter of Medicare enrollees receive their insurance through Medicare Advantage insurance (otherwise referred to as Part C). Medicare Advantage is a type of Medicare health plan offered by private insurance companies that contract with Medicare to provide beneficiaries with inpatient, outpatient, and prescription drug coverage.

\section{Prescription claims data used in this study}

Each year, the US Centers for Medicare and Medicaid Services process more than a billion prescription drug claims for its more than 37 million beneficiaries who receive their prescription drug insurance through the Medicare Part D program. Through an agreement with CMS, we obtained data on the prescription drug claims of a 20\% random sample of Medicare beneficiaries who had Part D coverage in 2010. Because not all Medicare beneficiaries obtain their prescription drug coverage through the Part D program — for example, of 50.7 million Medicare beneficiaries in 2012, 37.1 million had Part D coverage-our sample was not representative of Medicare overall but instead representative of the Part D population.

We identified prescription claims corresponding to an opioid drug (complete or partial opioid agonists and combination formulations) according to National Drug Code (see appendix table A); formulations used for antidiarrheal and antitussive purposes were excluded. The most commonly prescribed opioids were hydrocodone with acetaminophen (paracetamol) $(42.9 \%$ of all claims), oxycodone with acetaminophen (11.6\%), tramadol (11.9\%), oxycodone $(7.4 \%)$, morphine sulfate $(4.5 \%)$, and fentanyl $(4.2 \%)$. We did not have information on the indication for which the opioid was prescribed.

Beneficiary demographic data included information on age, sex, race (non-Hispanic white, non-Hispanic black, Hispanic, Asian, other including Native Americans), residence in a metropolitan area, and zipcode. Additional data on beneficiaries included whether or not a they received a low income subsidy at least one month of the year (a financial subsidy provided to qualifying beneficiaries with annual income below a government specified income threshold); whether or not a beneficiary received dual insurance coverage by Medicaid and Medicare at least one month of the year (provided to individuals with sufficiently low income that allows them to qualify for combined

Medicare-Medicaid insurance coverage that substantially reduces out of pocket expenditures); and whether or not a beneficiary received prescription coverage by Medicare Advantage versus a traditional Part D drug plan.

Drug claims were linked to information on each individual provider who prescribed the drugs, according to a unique encrypted provider identifier. For each prescription, the linked file provided information on provider type (such as physician, dentist, physician assistant) and physician specialty. Median household income in a beneficiary's residential zipcode was obtained from the 2010 US census. We included all beneficiaries who resided in the US, were continuously enrolled in Medicare during 2010, filled at least one prescription for an opioid that year, and had provider information for all filled opioid prescriptions. This resulted in a sample of 1808355 beneficiaries, implying that among 5214910 Medicare beneficiaries in the $20 \%$ sample with continuous enrollment during 2010, 34.7\% filled at least one opioid prescription. 


\section{Defining prescribing of opioids by multiple providers}

We counted the number of unique opioid providers for each beneficiary in 2010. We categorized beneficiaries into whether they filled only one prescription for an opioid or filled two or more prescriptions from one unique provider or two, three, or four or more providers. Patients can fill opioid prescriptions from more than one provider for several reasons, including a change in the primary provider responsible for opioid prescribing, the receipt of an opioid prescription from a provider covering the patient's customary provider, prescribing by consultant physicians or in settings such as a dentist's office or emergency room, or "doctor shopping." 19 Although several prior studies dichotomize prescribing of controlled substances by multiple providers into whether or not prescribing patterns reflect "doctor shopping," this categorization might obscure evidence of fragmented opioid prescribing that is equally important to consider.

\section{Descriptive analyses}

We conducted four descriptive analyses. First, we computed the frequency with which beneficiaries filled opioid prescriptions from multiple providers and described the characteristics of those who filled prescriptions from a single provider versus multiple providers. Second, we examined how opioid prescriptions were divided among a beneficiary's providers by estimating the mean number of opioid prescriptions provided by a beneficiary's dominant provider versus other providers. Third, to distinguish inappropriate prescribing from potentially appropriate prescribing (such as filling a prescription from a dentist after routine surgery), we estimated the proportion of beneficiaries who received concurrent opioid prescriptions from two or more providers. Concurrent use was defined as an opioid prescription from a second provider being filled before the supply of an existing opioid prescription from another provider had ended. Fourth, we analyzed the distribution of opioid prescriptions across physician specialties and non-physician providers (dentists, physician assistants, and others).

\section{Multivariate analysis of factors associated with multiple provider prescribing}

We estimated a beneficiary level logistic regression model to study beneficiary factors associated with prescribing of opioids by multiple providers. The dependent variable was a binary outcome of whether or not a beneficiary obtained opioid prescriptions from two or more providers in 2010. The independent variables included beneficiary's age, sex, race, and binary indicators for Medicare-Medicaid dual eligibility and low income subsidy for at least one month during the year, a binary indicator for Medicare Advantage (MA) rather than a stand-alone Part D drug plan for at least one month, a binary indicator for metropolitan residence, indicator variables for prescription therapeutic classes other than opioids (identified according to the NDC), median income of zipcode area, and indicators for the core based statistical area of the beneficiaries.

Dual eligibility for Medicare-Medicaid and receipt of low income subsidy were included to assess whether fragmentation of opioid prescribing was greater in this poorer population with characteristically high utilization of healthcare resources and fragmented care. ${ }^{31}{ }^{32}$ Coverage by a Medicare Advantage plan was included as an explanatory variable as these plans might offer more integrated care-and therefore lower the likelihood of opioid prescribing from multiple providers - than traditional Medicare enrollees. ${ }^{33-36}$ Finally, we included an indicator variable for whether a beneficiary's state had a prescription drug monitoring program in effect in 2010. Although the evidence is mixed, several studies suggest that state programs for monitoring prescription drugs are associated with lower rates of opioid diversion and prescribing by multiple providers. ${ }^{37-41}$

\section{Hospital admissions related to opioid use}

To study adverse outcomes associated with prescribing of opioids by multiple providers, we estimated a beneficiary level logistic regression of the association between multiple provider prescribing and any admission related to opioid use in 2010.

Admissions were identified from the linked Medicare provider analysis and review file - a data file obtained through agreement with the Centers for Medicare and Medicaid Services-which includes claims for all inpatient services used by traditional Medicare beneficiaries. Based on prior studies, admissions related to opioid use were identified from inpatient diagnosis codes for opioid drug dependence, opioid poisoning, respiratory failure, drug induced mental disorders (including alternation of consciousness and hallucinations), constipation, and malaise, fatigue, or lethargy. ${ }^{42-44}$

We focused on traditional Medicare beneficiaries with 12 months of enrollment ( $\mathrm{n}=1157423$ ) because data on inpatient admissions are not available for enrollees in the Medicare Advantage (that is, non-traditional Medicare) plan. The primary explanatory variables of interest included indicator variables for whether a beneficiary received opioid prescriptions from one, two, three, or four or more providers. In addition to adjusting for beneficiary age, sex, race, eligibility for Medicare-Medicaid dual and low income subsidy, and indicator variables for prescription therapeutic classes, we also adjusted for the total number of opioid prescriptions a beneficiary received. Among patients receiving the same number of opioid prescriptions annually, we therefore estimated whether patients receiving prescriptions from multiple providers were more likely to be admitted for a complication related to opioid use. We reported the adjusted percentage of beneficiaries with an opioid related admission according to the number of unique opioid providers.

All analyses were conducted with Stata version 12 (StataCorp, College Station, TX). The $95 \%$ confidence interval around reported means reflects 0.025 in each tail or $\mathrm{P} \leq 0.05$.

\section{Results}

Our sample included 1808355 beneficiaries with at least one filled prescription for an opioid in 2010. Prescribing of opioids by multiple providers was common: 418530 (23.1\%) beneficiaries filled opioid prescriptions from two providers, 171 $420(9.5 \%)$ from three providers, and 143344 (7.9\%) from four or more providers (table $1 \Downarrow$ ). Among 1208100 beneficiaries who filled more than one opioid prescription, $39.3 \%$ filled prescriptions from one provider, $34.6 \%$ from two providers, $14.2 \%$ from three providers, and $11.9 \%$ from four or more providers.

The mean number of opioid prescriptions per beneficiary increased substantially with multiple providers. Beneficiaries with opioid prescriptions from four or more providers had on average 15.2 opioid prescriptions (SD 9.8), compared with 7.1 (SD 7.1) and 10.1 (SD 7.9) among beneficiaries filling opioid prescriptions from two and three providers, respectively. More opioid prescriptions were filled by women (1 144 080/1 808 $355 ; 63.3 \%$ ), with little change in this percentage as beneficiaries received opioid prescriptions from more providers. Beneficiaries who filled opioid prescriptions from a larger number of 
providers were also younger. For example, 16.3\% (23 343/143 344) of beneficiaries filling opioid prescriptions from four or more providers were under age 45 compared with $6.5 \%$ (26 982/418 530) and 8.9\% (15 283/171 420) among beneficiaries filling opioid prescriptions from two and three providers, respectively ( $\mathrm{P}<0.001$ for test of joint significance). The proportion of beneficiaries filling an opioid prescription who were non-Hispanic black increased slightly as beneficiaries filled opioid prescriptions from more providers; $17.2 \%$ (24 $580 / 143344$ ) of beneficiaries who filled opioid prescriptions from four or more providers were non-Hispanic black compared with $12.7 \%$ (52 927/418 530) and 14.2\% (24 257/171 420) of beneficiaries who filled opioid prescriptions from two and three providers, respectively ( $\mathrm{P}<0.001$ for test of joint significance). Dual eligible beneficiaries comprised a larger proportion of beneficiaries who filled opioid prescriptions from four or more providers $(85807 / 143344 ; 59.9 \%)$ than beneficiaries who filled opioid prescriptions from only one provider (201 138/474 806; 42.4\%) $(\mathrm{P}<0.001)$.

The proportion of total prescriptions provided by a single dominant provider declined as beneficiaries received prescriptions from multiple providers (table $2 \Downarrow$ ). Beneficiaries who filled opioid prescriptions from two providers had an average of 5.56 prescriptions (95\% confidence interval 5.54 to 5.58 ) provided by the dominant provider and 1.57 (1.57 to 1.58 ) prescriptions provided by the second most dominant provider. In contrast, among beneficiaries who filled prescriptions from four or more providers, the dominant provider accounted for 7.93 prescriptions per beneficiary (7.89 to 7.97 ), less than half of the mean total prescriptions per beneficiary in this group (15.2).

A substantial proportion of beneficiaries received concurrent opioid prescriptions from two or more providers. For example, among 418530 beneficiaries with opioid prescriptions from two providers, 120263 (28.7\%, 95\% confidence interval $28.6 \%$ to $28.9 \%$ ) received concurrent prescriptions from both providers. The frequency of concurrent prescribing increased with the number of providers. For instance, among 171420 beneficiaries with opioid prescriptions from three providers, 89961 (52.5\%, $52.2 \%$ to $52.7 \%$ ) received concurrent prescriptions from two or more of those providers. Furthermore, among 143344 beneficiaries with opioid prescriptions from four or more providers, $110671(77.2 \%, 76.9 \%$ to $77.4 \%)$ received concurrent prescriptions from two or more of those providers.

Most beneficiaries with multiple opioid providers received prescriptions from internists or family practitioners, followed by surgeons, emergency medicine physicians, and physician assistants (appendix table B). Although anesthesiologists and pain medicine specialists were an uncommon source of opioid prescriptions for beneficiaries with only one provider (11 $003 / 474806 ; 2.3 \%$ ), the mean number of prescriptions per beneficiary was highest among this group of physicians (12.3 prescriptions, $95 \%$ confidence interval 12.1 to 12.5 ).

\section{Factors associated with multiple provider prescribing}

Multiple provider prescribing was more common among younger beneficiaries in both unadjusted and adjusted analyses (table $3 \Downarrow$ ). For instance, the adjusted odds ratio for filling an opioid prescription from multiple providers was 3.35 (95\% confidence interval 3.28 to 3.42 ) among beneficiaries aged under 45 (reference group age $\geq 85$ ) compared with 1.55 (1.53 to 1.57 ) among those aged 65-74.
Non-Hispanic black patients, Hispanics, and those of other races were more likely to fill opioid prescriptions from multiple providers compared with non-Hispanic white patients. For example, the adjusted odds ratio of filling an opioid prescription from multiple providers was 1.20 (95\% confidence interval 1.18 to 1.22 ) among non-Hispanic black patients compared with non-Hispanic white patients. Women were slightly less likely than men to fill opioid prescriptions from multiple providers. Beneficiaries who lived in non-metropolitan areas, received low income subsidies, or were dually eligible for Medicare and Medicaid were also generally less likely to fill opioid prescriptions from multiple providers.

Beneficiaries filling prescriptions for antineoplastic drugs, stimulants, other central nervous system drugs, neuromuscular drugs, and non-narcotic analgesic drugs were more likely to fill opioid prescriptions from multiple providers than beneficiaries who did not use drugs in these classes. For example, the odds ratio for filling opioid prescriptions from multiple providers was 1.28 (95\% confidence interval 1.27 to 1.29 ) for beneficiaries who filled at least one prescription for a neuromuscular drug compared with those who did not.

Beneficiaries enrolled in Medicare Advantage plans were slightly more likely than beneficiaries enrolled in traditional Part D plans to fill opioid prescriptions from multiple providers. The association between state prescription drug monitoring plans and filling opioid prescriptions from multiple providers was not significant.

\section{Opioid related admission to hospital}

Multiple provider prescribing was positively associated with annual rates of admission to hospital related to opioid use in both unadjusted and adjusted analyses (table $4 \Downarrow$ ). Among 314 132 beneficiaries with one unique provider, 5111 (unadjusted $1.63 \%, 95 \%$ confidence interval $1.58 \%$ to $1.67 \%$ ) had an opioid related admission in 2010, compared with 5598/268 753 beneficiaries $(2.08 \%, 2.03 \%$ to $2.14 \%)$ with two providers, $3209 / 111830$ beneficiaries $(2.87 \%, 2.77 \%$ to $2.97 \%)$ with three providers, and $4735 / 98048$ beneficiaries $(4.83 \%, 4.70 \%$ to $4.96 \%$ ) with four or more providers. Statistical tests for an increasing trend across categories were significant at $\mathrm{P}<0.01$ for each comparison (for example, rates of admission among patients with two $v$ one provider, three $v$ two providers, and four or more $v$ three providers). In adjusted analyses, results of statistical tests for an increasing trend across categories were again significant at $\mathrm{P}<0.01$ for each comparison.

\section{Discussion}

Using prescription claims data from a national sample of US Medicare beneficiaries in 2010, we found that concurrent prescribing of opioids by multiple providers was common. More importantly, patients' receipt of prescription opioids from multiple providers was strongly associated with higher rates of admission to hospital related to opioid use. For example, among patients utilizing the same quantity of prescribed opioid drug over the course of a year, those who received prescription opioids from four or more unique providers had twice the annual rate of admission than those who received prescription opioids from only one provider (3.2\% v 1.6\% admitted in a year).

Multiple provider opioid prescribing was highest among younger beneficiaries, black patients, and those who filled prescriptions for stimulants, other central nervous system drugs, non-narcotic analgesic drugs, neuromuscular drugs, or antineoplastic drugs. 


\section{Interpretation of findings}

While patients might appropriately fill opioid prescriptions from multiple providers for reasons such as a change in their primary opioid provider, prescribing by a covering physician, or prescribing in settings such as a dentist's office or emergency room, multiple provider prescribing might also reflect fragmented care-whereby no specific physician is solely responsible for a patient's needs for opioid prescription-or intentional doctor shopping by patients. ${ }^{19}$ Although prior studies of multiple provider opioid prescribing have specifically attempted to identify patterns of doctor shopping in younger adult populations, ${ }^{18-24}$ such prescribing among elderly people-who comprise nearly $75 \%$ of the Medicare population we studied, as defined by age $>65$ - is concerning because of increased adverse events associated with opioid use in this population, ${ }^{78}$ in part due to changes in drug metabolism and excretion that occur with ageing as well as frequent poly-pharmacy. ${ }^{29}{ }^{30}$ While guidelines recommend prescribing of opioids by a single provider, ${ }^{45}{ }^{46}$ we found not only that prescribing of opioids by multiple providers was common in Medicare but that concurrent opioid prescribing by multiple providers was also common. Multiple provider prescribing was associated with more admissions related to opioid use, and, moreover, patients prescribed opioids from multiple providers were also often prescribed potentially inappropriate drugs for elderly and disabled patients-for example, benzodiazepines, antipsychotic drugs, and skeletal muscle relaxants. ${ }^{29} 47$

\section{Implications for healthcare professionals and policymakers}

For physicians and other healthcare professionals, our findings not only highlight the dramatic prevalence of multiple provider opioid prescribing among elderly and disabled people but, more importantly, show the adverse health outcomes associated with this fragmented prescribing. Our findings reinforce the need to educate patients about the risks associated with obtaining opioid prescriptions from multiple providers. For policymakers, our findings suggest the potential importance of new state efforts, such as those in Massachusetts, to provide physicians with the ability to view online the prescription histories of their patients in the past year. While not yet formally evaluated because of the recent nature of these programs, such efforts to monitor prescription drug targeted at physicians have the potential to reduce doctor shopping by allowing physicians to better monitor, identify, and deal with fragmented opioid prescribing directly. Our findings also suggest that other existing efforts to monitor prescription drugs implemented by states-such as those specifically designed to reduce illicit opioid diversion-should consider expansion to identify patterns of opioid prescribing that are not necessarily illicit but might nonetheless reflect potentially harmful fragmented prescribing. Finally, our results also suggest a potentially greater role for pharmacists to serve as gatekeepers to prescription opioid drugs. For example, pharmacists can use computerized databases of prescription filling integrated into their practice to notify all providers when a patient concurrently fills two or more prescriptions for an opioid from multiple providers.

\section{Strengths and weaknesses in relation to other studies}

Our study had several strengths and weaknesses. Prior studies of multiple provider prescribing have generally been limited by focusing on analyses of particular US states rather than the nation as a whole, ${ }^{192}{ }^{24}$ have not studied characteristics of patients and providers involved that are associated with multiple provider prescribing, have not focused on elderly and disabled people (such as Medicare) who are at highest risk of complications associated with opioid drugs, and, most importantly, have not studied adverse patient outcomes such as opioid related admissions to hospital associated with multiple provider prescribing. ${ }^{18} 23$

Nonetheless, our study had several limitations. First, ideally we would have studied a representative sample of all individuals in the US prescribed opioids rather than those in Medicare and been able to separately estimate the prevalence of multiple provider prescribing across Medicare and non-Medicare populations as well as the possibly distinct effects of multiple provider prescribing on patient outcomes such as opioid related admissions. Importantly, however, our estimated rates of multiple provider opioid prescribing were similar to rates in other studies that were not limited to the Medicare population. ${ }^{18-24}$ Second, we could not definitively determine whether multiple provider prescribing reflected appropriate prescribing, fragmented care, or doctor shopping. While prescribing by multiple providers can often be appropriate, nearly a quarter of Medicare beneficiaries with more than one opioid prescription in 2010 received prescriptions from three or more providers, and, among these beneficiaries, nearly $64 \%$ received concurrent opioid prescriptions from different providers. Both findings suggest that fragmented prescribing of opioids is common. Third, although we showed higher rates of opioid related admissions among beneficiaries who receive opioids from multiple providers, we could not determine whether this association reflects a direct impact of fragmented opioid prescribing on admissions or is due to selection bias among these beneficiaries. While is important to distinguish these two possibilities, our findings nonetheless highlight the importance to clinicians of identifying beneficiaries who receive opioid prescriptions from multiple providers as these individuals are at highest risk of opioid related admissions. Fourth, our analysis of adverse clinical outcomes associated with multiple provider opioid prescribing was limited to opioid related admissions and did not include mortality. Finally, our analysis did not distinguish between multiple provider prescribing of high versus low potency opioids or differing opioid doses. The ideal measure of opioid use would be to report total milligrams of morphine equivalency, to capture not only differences in doses across opioid prescriptions but also differences in potency of different opioids.

\section{Conclusions}

Despite its limitations, our study suggests that concurrent prescribing of opioids by multiple providers is common among Medicare beneficiaries and is associated with higher rates of hospital admissions related to use. Education of patients about the risks of obtaining prescription opioids from multiple providers, combined with enhancement of state efforts to monitor prescription drugs that allow access by providers to prescription databases at the point of care might be useful in curbing this practice.

Contributors: All authors contributed to the design and conduct of the study, data collection and management, analysis interpretation of the data; and preparation, review, or approval of the manuscript. ABJ is guarantor.

Funding: This study was funded by the National Institutes of Health, the National Institute on Aging, and the University of Minnesota. The research conducted was independent of any involvement from the sponsors of the study. Study sponsors were not involved in study design, 


\section{What is already known on this topic}

The frequency with which patients obtain opioid prescriptions from multiple healthcare providers has received increasing attention Although opioids are associated with adverse events in elderly patients, estimates of the frequency and characteristics of multiple provider opioid prescribing among Medicare beneficiaries are unknown, as are associated outcomes

\section{What this study adds}

In the United States, Medicare beneficiaries often receive prescriptions for opioid drugs from multiple providers; of those with four or more opioid providers, more than three quarters receive concurrent opioid prescriptions from multiple providers

Beneficiaries receiving opioids from multiple providers are also more likely to be prescribed other drugs that have high rates of adverse effects and misuse

Opioid prescribing by multiple providers is associated with higher rates of opioid related admissions

data interpretation, writing, or the decision to submit the article for publication.

Competing interests: All authors have completed the ICMJE uniform disclosure form at www.icmje.org/coi_disclosure.pdf (available on request from the corresponding author) and declare: $\mathrm{ABJ}$ had support from the Office of the Director, National Institutes of Health (NIH Early Independence Award, Grant 1DP5OD017897-01) for the submitted work, PKM had support from the National Institute on Aging (Grant 5K01AG036740) and a University of Minnesota Academic Health Center Faculty Development Grant, and DG had support from the National Institute on Aging (Grant 5P01AG033559).

Ethical approval: Because all data were de-identified, human subjects review was not required by the institutional review board at the University of Southern California.

Transparency: The lead author (the manuscript's guarantor, ABJ) affirms that the manuscript is an honest, accurate, and transparent account of the study being reported; that no important aspects of the study have been omitted; and that any discrepancies from the study as planned (and, if relevant, registered) have been explained.

Data sharing: No additional data available.

1 Caudill-Slosberg MA, Schwartz LM, Woloshin S. Office visits and analgesic prescriptions for musculoskeletal pain in US: 1980 vs. 2000. Pain 2004;109:514-9.

2 Sullivan MD, Edlund MJ, Fan MY Devries A, Brennan Braden J, Martin BC. Trends in use of opioids for non-cancer pain conditions 2000-2005 in commercial and Medicaid insurance plans: the TROUP study. Pain 2008;138:440-9.

3 Campbell Cl, Weisner C, Leresche L, Ray GT, Saunders K, Sullivan MD, et al. Age and gender trends in long-term opioid analgesic use for noncancer pain. Am J Public Health 2010;100:2541-7.

4 Novak S, Nemeth WC, Lawson KA. Trends in medical use and abuse of sustained-release opioid analgesics: a revisit. Pain Med 2004:5:59-65.

5 Alexander GC, Kruszewski SP, Webster DW. Rethinking opioid prescribing to protect patient safety and public health. JAMA 2012;308:1865-6.

6 United States Senate Committee on Finance. Baucus, Grassley seek answers about opioid manufacturers' ties to medical groups. 2012. www.finance.senate.gov/newsroom/ chairman/release.

7 Okie S. A flood of opioids, a rising tide of deaths. N Engl J Med 2010:363:1981-5.

8 Dunn KM, Saunders KW, Rutter CM, Banta-Green CJ, Merrill JO, Sullivan MD, et al. Opioid prescriptions for chronic pain and overdose: a cohort study. Ann Intern Med 2010;152:85-92.

9 Prescription pain reliever abuse: agencies have begun coordinating education efforts, but need to asses effectiveness. United States Government Accountability Office, 2011:73. www.gao.gov/assets/590/587301.pdf.

10 Ling W, Mooney L, Hillhouse M. Prescription opioid abuse, pain and addiction: clinical issues and implications. Drug Alcohol Rev 2011;30:300-5.

11 Centers for Disease Control. Vital signs: overdoses of prescription opioid pain relievers-United States, 1999-2008. MMWR Morb Mortal Wkly Rep 2011;60:1487-92.

12 Paulozzi LJ, Budnitz DS, Xi Y. Increasing deaths from opioid analgesics in the United States. Pharmacoepidemiol Drug Saf 2006;15:618-27.

13 Paulozzi LJ, Ryan GW. Opioid analgesics and rates of fatal drug poisoning in the United States. Am J Prev Med 2006;31:506-11

14 Saunders KW, Dunn KM, Merrill JO, Sullivan M, Weisner C, Braden JB, et al. Relationship of opioid use and dosage levels to fractures in older chronic pain patients. $J$ Gen Intern Med 2010;25:310-5.

15 Solomon DH, Rassen JA, Glynn RJ, Lee J, Levin R, Schneeweiss S. The comparative safety of analgesics in older adults with arthritis. Arch Intern Med 2010;170:1968-76.

16 Miller M, Sturmer T, Azrael D, Levin R, Solomon DH. Opioid analgesics and the risk of fractures in older adults with arthritis. J Am Geriatr Soc 2011;59:430-8.

17 Dhalla IA, Persaud N, Juurlink DN. Facing up to the prescription opioid crisis. BMJ 2011;343:d5142.

18 Cepeda MS, Fife D, Berlin JA, Mastrogiovanni G, Yuan Y. Characteristics of prescribers whose patients shop for opioids: results from a cohort study. J Opioid Manag 2012;8:285-91.

19 Wilsey BL, Fishman SM, Gilson AM, Casamalhuapa C, Baxi H, Zhang H, et al. Profiling multiple provider prescribing of opioids, benzodiazepines, stimulants, and anorectics. Drug Alcohol Depend 2010;112:99-106.
20 Katz N, Panas L, Kim M, Audet AD, Bilansky A, Eadie J, et al. Usefulness of prescription monitoring programs for surveillance-analysis of schedule II opioid prescription data in Massachusetts, 1996-2006. Pharmacoepidemiol Drug Saf 2010;19:115-23.

21 Parente ST, Kim SS, Finch MD, Schloff LA, Rector TS, Seifeldin R, et al. Identifying controlled substance patterns of utilization requiring evaluation using administrative claims data. Am J Manag Care 2004;10:783-90.

22 Wilsey BL, Fishman SM, Gilson AM, Casamalhuapa C, Baxi H, Lin TC, et al. An analysis of the number of multiple prescribers for opioids utilizing data from the California Prescription Monitoring Program. Pharmacoepidemiol Drug Saf 2011;20:1262-8.

23 Cepeda MS, Fife D, Chow W, Mastrogiovanni G, Henderson SC. Assessing opioid shopping behaviour: a large cohort study from a medication dispensing database in the US. Drug Saf 2012;35:325-34.

24 Peirce GL, Smith MJ, Abate MA, Halverson J. Doctor and pharmacy shopping for controlled substances. Med Care 2012;50:494-500.

25 Hamilton HJ, Gallagher PF, O'Mahony D. Inappropriate prescribing and adverse drug events in older people. BMC Geriatr 2009;9:5

26 Green JL, Hawley JN, Rask KJ. Is the number of prescribing physicians an independent risk factor for adverse drug events in an elderly outpatient population? Am J Geriatr Pharmacother 2007:5:31-9.

27 Wilson IB, Schoen C, Neuman P, Strollo MK, Rogers WH, Chang H, et al. Physician-patient communication about prescription medication nonadherence: a 50 -state study of America's seniors. J Gen Intern Med 2007;22:6-12.

28 Hajjar ER, Hanlon JT, Sloane RJ, Lindblad CI, Pieper CF, Ruby CM, et al. Unnecessary drug use in frail older people at hospital discharge. J Am Geriatr Soc 2005:53:1518-23.

29 Curtis LH, Ostbye T, Sendersky V, Hutchison S, Dans PE, Wright A, et al. Inappropriate prescribing for elderly Americans in a large outpatient population. Arch Intern Med 2004;164:1621-5.

30 Stewart RB, Cooper JW. Polypharmacy in the aged. Practical solutions. Drugs Aging 1994:4:449-61.

31 Moon S, Shin J. Health care utilization among Medicare-Medicaid dual eligibles: a count data analysis. BMC Public Health 2006:6:88.

32 Jacobson G, Neuman T, Damico A. Medicare's role for dual eligible beneficiaries. Kaiser Family Foundation Medicare Policy Report, 2012:1-14.

33 Basu J, Friedman B, Burstin H. Managed care and preventable hospitalization among Medicaid adults. Health Serv Res 2004;39:489-510.

34 Brennan N, Shepard M. Comparing quality of care in the Medicare program. Am J Manag Care 2010;16:841-8.

35 Lemieux J, Sennett C, Wang R, Mulligan T, Bumbaugh J. Hospital readmission rates in Medicare Advantage plans. Am J Manag Care 2012;18:96-104.

36 Cohen R, Lemieux J, Schoenborn J, Mulligan T. Medicare Advantage Chronic Special Needs Plan boosted primary care, reduced hospital use among diabetes patients. Health Aff (Millwood) 2012;31:110-9.

37 Gilson AM, Fishman SM, Wilsey BL, Casamalhuapa C, Baxi H. Time series analysis of California's prescription monitoring program: impact on prescribing and multiple provider episodes. J Pain 2012;13:103-11.

38 Pearson SA, Soumerai S, Mah C, Zhang F, Simoni-Wastila L, Salzman C, et al. Racial disparities in access after regulatory surveillance of benzodiazepines. Arch Intern Med 2006;166:572-9.

39 Paulozzi LJ, Kilbourne EM, Desai HA. Prescription drug monitoring programs and death rates from drug overdose. Pain Med 2011;12:747-54.

40 Pradel V, Frauger E, Thirion X, Ronfle E, Lapierre V, Masut A, et al. Impact of a prescription monitoring program on doctor-shopping for high dosage buprenorphine. Pharmacoepidemiol Drug Saf 2009;18:36-43.

41 Wang J, Christo PJ. The influence of prescription monitoring programs on chronic pain management. Pain Physician 2009:12:507-15.

42 Coben JH, Davis SM, Furbee PM, Sikora RD, Tillotson RD, Bossarte RM. Hospitalizations for poisoning by prescription opioids, sedatives, and tranquilizers. Am J Prev Med 2010;38:517-24

43 Hartung DM, Middleton L, Haxby DG, Koder M, Ketchum KL, Chou R. Rates of adverse events of long-acting opioids in a state Medicaid program. Ann Pharmacother 2007;41:921-8.

44 Bourgeois FT, Shannon MW, Valim C, Mandl KD. Adverse drug events in the outpatient setting: an 11-year national analysis. Pharmacoepidemiol Drug Saf 2010;19:901-10.

45 Interagency guideline on opioid dosing for chronic non-cancer pain: an educational aid to improve care and safety with opioid therapy. Washington State Agency Medical Director's Group, 2010. www.agencymeddirectors.wa.gov/Files/OpioidGdline.pdf.

46 Chou R, Fanciullo GJ, Fine PG, Adler JA, Ballantyne JC, Davies P, et al. Clinical guidelines for the use of chronic opioid therapy in chronic noncancer pain. J Pain 2009;10:113-30.

47 Dalleur O, Boland B, Spinewine A. 2012 updated Beers criteria: greater applicability to Europe? J Am Geriatr Soc 2012;60:2188-90.

Accepted: 28 January 2014 
This is an Open Access article distributed in accordance with the Creative Commons Attribution Non Commercial (CC BY-NC 3.0) license, which permits others to distribute, remix, adapt, build upon this work non-commercially, and license their derivative works on different terms, provided the original work is properly cited and the use is non-commercial. See: http://creativecommons.org/licenses/by-nc/3.0/. 


\section{Tables}

\begin{tabular}{|c|c|c|c|c|c|c|}
\hline & \multirow[b]{2}{*}{ Entire sample } & \multirow{2}{*}{$\begin{array}{c}1 \\
\text { prescription only }\end{array}$} & \multicolumn{4}{|c|}{$>1$ prescription } \\
\hline & & & 1 provider & 2 providers & 3 providers & $\geq 4$ providers \\
\hline No of beneficiaries & 1808355 & 600255 & 474806 & 418530 & 171420 & 143344 \\
\hline Mean (SD) No of opioid prescriptions & $6.1(7.4)$ & $1(0)$ & $7.5(6.9)$ & $7.1(7.1)$ & $10.1(7.9)$ & $15.2(9.8)$ \\
\hline \multicolumn{7}{|l|}{ Age (years): } \\
\hline$<45$ & $6.4(116198)$ & $5.1(30371)$ & $4.3(20219)$ & $6.5(26982)$ & $8.9(15283)$ & $16.3(23343)$ \\
\hline $45-54$ & $9.3(167606)$ & $5.2(30966)$ & $8.8(41947)$ & $10.0(41933)$ & $13.7(23462)$ & $20.4(29298)$ \\
\hline $55-64$ & $11.8(214012)$ & $7.4(44351)$ & $13.0(61670)$ & $13.1(54852)$ & $15.8(27030)$ & $18.2(26109)$ \\
\hline $65-74$ & $38.0(687961)$ & $44.3(265763)$ & $35.4(167888)$ & $37.3(156058)$ & $34.4(59030)$ & $27.4(39222)$ \\
\hline $75-84$ & $24.7(446710)$ & $28.0(167999)$ & $25.9(123123)$ & $24.1(100687)$ & $20.4(35012)$ & $13.9(19889)$ \\
\hline$\geq 85$ & $9.7(175868)$ & $10.1(60805)$ & $12.6(59959)$ & $9.1(38018)$ & $6.8(11603)$ & $3.8(5483)$ \\
\hline Mean (SD) age (years) & $68.5(13.6)$ & $70.5(12.6)$ & $70.1(13.1)$ & $68.1(13.6)$ & $65.4(14.2)$ & $60.1(15.0)$ \\
\hline Female & $63.3(1144080)$ & $59.8(358672)$ & $65.3(309953)$ & $64.5(270104)$ & $65.4(112108)$ & $65.1(93243)$ \\
\hline Male & 36.7 (664 275) & $40.3(241583)$ & $34.7(164853)$ & $35.5(148426)$ & 34.6 (59 312) & $35.0(50$ 101) \\
\hline \multicolumn{7}{|l|}{ Race: } \\
\hline Non-Hispanic white & 81.1 (1 466358$)$ & 81.1 (486 892) & $82.3(390740)$ & $81.2(339970)$ & $80.2(137535)$ & $77.6(111221)$ \\
\hline Non-Hispanic black & $12.4(223799)$ & $11.1(66758)$ & $11.6(55277)$ & $12.7(52927)$ & $14.2(24257)$ & $17.2(24580)$ \\
\hline Asian & $1.6(28820)$ & $2.3(13643)$ & $1.5(7269)$ & $1.3(5439)$ & $0.9(1566)$ & $0.6(903)$ \\
\hline Hispanic & $3.0(54024)$ & $3.3(19706)$ & $2.8(13300)$ & $3.0(12460)$ & $2.9(4882)$ & $2.6(3676)$ \\
\hline Other & $2.0(35354)$ & $2.2(13256)$ & $1.7(8220)$ & $1.9(7734)$ & $1.9(3180)$ & $2.1(2964)$ \\
\hline \multicolumn{7}{|l|}{ Subsidy/dual eligibility status: } \\
\hline Non-eligible for subsidy & $54.1(978770)$ & $65.4(392611)$ & $50.9(241517)$ & $52.3(218$ 831) & $45.5(78048)$ & $33.3(47763)$ \\
\hline Low income subsidy only & $6.1(109929)$ & $5.0(29726)$ & $6.8(32151)$ & $6.4(26746)$ & 6.7 (11 532) & $6.8(9774)$ \\
\hline Medicare-Medicaid dual eligible & $39.8(719656)$ & $29.6(177918)$ & $42.4(201138)$ & $41.3(172953)$ & $47.7(81840)$ & $59.9(85807)$ \\
\hline Medicare Advantage beneficiary & 35.7 (645 502) & $39.1(234537)$ & $33.7(160030)$ & $35.5(148454)$ & $34.3(58759)$ & $30.5(43722)$ \\
\hline \multicolumn{7}{|l|}{ Other drug utilization: } \\
\hline Antineoplastic & $4.9(88874)$ & $4.1(24293)$ & $4.9(23216)$ & $5.3(22$ 198) & $5.8(9964)$ & $6.4(9203)$ \\
\hline Stimulant & $1.5(27260)$ & $0.8(4760)$ & $1.4(6828)$ & $1.7(6934)$ & $2.2(3833)$ & $3.4(4905)$ \\
\hline Psychotherapeutic & $7.3(131992)$ & $6.1(36334)$ & $8.5(40519)$ & $7.3(30324)$ & $7.5(12882)$ & $8.3(11933)$ \\
\hline Central nervous system medication & 49.9 (903 081) & $36.3(218005)$ & $52.7(250080)$ & $53.9(225708)$ & $62.0(106279)$ & $71.9(103009)$ \\
\hline Neuromuscular & $39.8(720$ 103) & $25.1(150788)$ & $40.7(193058)$ & $44.6(186688)$ & $54.4(93276)$ & $67.2(96293)$ \\
\hline Non-opioid analgesics & $37.3(675265)$ & $31.1(186835)$ & $35.6(169158)$ & $40.3(168482)$ & $45.0(77$ 195) & $51.3(73595)$ \\
\hline
\end{tabular}


Table 2/ Number of opioid prescriptions supplied by each provider per beneficiary. Figures are shown with $95 \%$ confidence interval

\begin{tabular}{|c|c|c|c|c|c|}
\hline & \multirow[b]{2}{*}{1 prescription only } & \multicolumn{4}{|c|}{$>1$ prescription } \\
\hline & & 1 provider & 2 providers & 3 providers & $\geq 4$ providers \\
\hline No of beneficiaries & 600255 & 474806 & 418530 & 171420 & 143344 \\
\hline Mean No of prescriptions from dominant provider & 1 & 7.50 (7.48 to 7.52$)$ & $5.56(5.54$ to 5.58$)$ & 6.69 (6.66 to 6.72$)$ & 7.93 (7.89 to 7.97$)$ \\
\hline Mean No of prescriptions from second ranked provider & - & - & $1.57(1.57$ to 1.58$)$ & 2.16 (2.15 to 2.17$)$ & 3.05 (3.04 to 3.07 ) \\
\hline Mean No of prescriptions from third ranked provider & - & - & - & $1.20(1.20$ to 1.20$)$ & $1.73(1.72$ to 1.73$)$ \\
\hline Mean No of prescriptions from fourth ranked provider & - & - & - & - & $1.24(1.24$ to 1.24$)$ \\
\hline Mean No of prescriptions from fifth or lower ranked provider & - & - & - & - & 2.57 (2.55 to 2.59$)$ \\
\hline
\end{tabular}


Table 3| Factors associated with prescribing of opioids by multiple providers in beneficiaries who obtained prescriptions from one or more providers. Results are from beneficiary level logistic regression of factors associated with whether or not beneficiary received prescriptions from multiple providers

\begin{tabular}{|c|c|c|c|}
\hline$<45$ & 76.4 (65 608/85 827) & 3.53 (3.46 to 3.60$)$ & 3.35 (3.28 to 3.42 ) \\
\hline $45-54$ & $69.3(94693 / 136$ 640) & 2.46 (2.42 to 2.50$)$ & 2.28 (2.24 to 2.32 ) \\
\hline $55-64$ & 63.7 (107 991/169 661) & 1.91 (1.88 to 1.93$)$ & $1.73(1.70$ to 1.76$)$ \\
\hline $65-74$ & $60.2(254$ 310/422 198) & 1.65 (1.63 to 1.67$)$ & 1.55 (1.53 to 1.57$)$ \\
\hline $75-84$ & 55.8 (155 588/278 711) & 1.38 (1.36 to 1.39$)$ & 1.32 (1.31 to 1.34$)$ \\
\hline$\geq 85$ & $47.9(55$ 104/115 063) & Reference & Reference \\
\hline \multicolumn{4}{|l|}{ Race: } \\
\hline Non-Hispanic white & 60.1 (588 726/979 466) & Reference & Reference \\
\hline Non-Hispanic black & $64.8(101764 / 157$ 041) & $1.22(1.21$ to 1.24$)$ & 1.20 (1.18 to 1.22$)$ \\
\hline Asian & $52.1(7908 / 15$ 177) & $0.72(0.70$ to 0.75$)$ & 0.77 (0.75 to 0.80$)$ \\
\hline Hispanic & $61.2(21018 / 34318)$ & 1.05 (1.03 to 1.07$)$ & 1.07 (1.04 to 1.09$)$ \\
\hline Other & $62.8(13878 / 22$ 098) & 1.12 (1.09 to 1.15$)$ & 1.07 (1.04 to 1.10$)$ \\
\hline \multicolumn{4}{|l|}{ Sex: } \\
\hline Male & $61.0(257$ 839/422 692) & Reference & Reference \\
\hline Female & $60.5(475$ 455/785 408) & 0.98 (0.97 to 0.99$)$ & 0.98 (0.97 to 0.99$)$ \\
\hline \multicolumn{4}{|l|}{ Metropolitan area: } \\
\hline Yes & 61.4 (555 549/905 201) & Reference & Reference \\
\hline No & 58.7 (177 745/302 899) & 0.89 (0.88 to 0.90$)$ & 0.81 (0.68 to 0.97 ) \\
\hline Median household income in zipcode ${ }^{*}$ & - & $1.02(1.01$ to 1.02$)$ & $1.03(1.03$ to 1.04$)$ \\
\hline \multicolumn{4}{|l|}{ Subsidy/dual-eligible status: } \\
\hline Non-eligible for subsidy & $58.8(344$ 642/586 159) & Reference & Reference \\
\hline Low-income subsidy only & $59.9(48$ 052/80 203) & $1.05(1.03$ to 1.06$)$ & $0.88(0.87$ to 0.90$)$ \\
\hline Medicare-Medicaid dual eligible & $62.9(340$ 600/541 738) & $1.19(1.18$ to 1.20$)$ & 0.91 (0.90 to 0.91$)$ \\
\hline \multicolumn{4}{|l|}{ Other drug utilization: } \\
\hline Anti-neoplastic agents (no) & $60.5(691929 / 1143519)$ & Reference & Reference \\
\hline Anti-neoplastic agents (yes) & $64.1(41365 / 64581)$ & $1.16(1.14$ to 1.18$)$ & 1.17 (1.15 to 1.92$)$ \\
\hline Stimulants (no) & $60.5(717622 / 1185600)$ & Reference & Reference \\
\hline Stimulants (yes) & $69.7(15672 / 22500)$ & $1.50(1.45$ to 1.54$)$ & 1.04 (1.01 to 1.07$)$ \\
\hline $\begin{array}{l}\text { Psychotherapeutic/neurological agents } \\
\text { (no) }\end{array}$ & $61.0(678$ 155/1 112442$)$ & Reference & Reference \\
\hline $\begin{array}{l}\text { Psychotherapeutic/neurological agents } \\
\text { (yes) }\end{array}$ & $57.6(55$ 139/95 658) & 0.87 (0.86 to 0.88$)$ & 0.87 (0.86 to 0.89$)$ \\
\hline Central nervous system drugs (no) & $57.0(298$ 298/523 024) & Reference & Reference \\
\hline Central nervous system drugs (yes) & $63.5(434$ 996/685 076) & 1.31 (1.30 to 1.32$)$ & $1.10(1.09$ to 1.10$)$ \\
\hline Neuromuscular agents (no) & $55.9(357037 / 638$ 785) & Reference & Reference \\
\hline Neuromuscular agents (yes) & $66.1(376257 / 569$ 315) & 1.54 (1.53 to 1.55$)$ & $1.28(1.27$ to 1.29$)$ \\
\hline Non-narcotic analgesic (no) & $57.5(414022 / 719670)$ & Reference & Reference \\
\hline Non-narcotic analgesic (yes) & 65.4 (319 272/488 430) & $1.39(1.38$ to 1.40$)$ & $1.26(1.25$ to 1.27$)$ \\
\hline \multicolumn{4}{|l|}{ Medicare Advantage: } \\
\hline No & $60.5(482359 / 797$ 135) & Reference & Reference \\
\hline Yes & $61.1(250935 / 410965)$ & $1.02(1.02$ to 1.03$)$ & $1.07(1.06$ to 1.08$)$ \\
\hline \multicolumn{4}{|c|}{ State prescription drug monitoring program: } \\
\hline No & $60.9(219887 / 361383)$ & Reference & Reference \\
\hline Yes & $60.6(513407 / 846$ 717) & 1.01 (1.00 to 1.02$)$ & 1.01 (0.99 to 1.02$)$ \\
\hline
\end{tabular}


Table 3 (continued)

Odds ratio $(95 \% \mathrm{Cl})$

${ }^{*}$ Continuous rather than categorical variable. Odds ratios reflect effect of $\$ 1$ increase in median zipcode household income on odds of filling opioid prescription from multiple providers $v$ one provider. 
Table 4| Unadjusted and adjusted percentage of Medicare beneficiaries with admission to hospital related to opioid use in 2010, according to number of unique opioid providers

\begin{tabular}{|c|c|c|c|c|}
\hline \multirow{2}{*}{$\begin{array}{l}\text { No of unique opioid } \\
\text { providers }\end{array}$} & \multirow[b]{2}{*}{ No of beneficiaries } & \multirow{2}{*}{$\begin{array}{c}\text { No of opioid related } \\
\text { admissions }\end{array}$} & \multicolumn{2}{|c|}{ Percent admitted to hospital ${ }^{\star}(95 \% \mathrm{Cl})$} \\
\hline & & & Unadjusted & Adjusted $†$ \\
\hline 1 & 314132 & 5111 & 1.63 (1.58 to 1.67$)$ & $1.64(1.59$ to 1.69$)$ \\
\hline 2 & 268753 & 5598 & $2.08(2.03$ to 2.14$)$ & $1.97(1.92$ to 2.02$)$ \\
\hline 3 & 111830 & 3209 & 2.87 (2.77 to 2.97 ) & 2.33 (2.25 to 2.41$)$ \\
\hline$\geq 4$ & 98048 & 4735 & $4.83(4.70$ to 4.96$)$ & $3.24(3.14$ to 3.33$)$ \\
\hline
\end{tabular}

*Rates computed for traditional Medicare beneficiaries in 2010. Admission information was not available for Medicare Advantage enrolees.

†Adjusted rates based on logistic model in which binary outcome variable was any opioid related admission in 2010. Primary explanatory variables of interest included indicator variables for whether beneficiary received opioid prescriptions from 1, 2, 3, or $\geq 4$ providers. Other independent variables included beneficiary age, sex, race, binary indicators for Medicare-Medicaid dual eligibility and low income subsidy for at least one month during year, binary indicator for metropolitan residence, indicator variables for prescription therapeutic classes other than opioids (identified according to National Drug Code), median income of zipcode area, and indicators for core based statistical area of beneficiaries. 